\title{
EDUCAÇÃO FÍSICA NAS DIRETRIZES DA UNESCO: O PARADIGMA DA APTIDÃO FíSICA E DA SAÚDE NA FORMAÇÃO DO CAPITAL HUMANO
}

\author{
PHYSICAL EDUCATION IN UNESCO GUIDELINES: THE PARADIGM OF \\ PHYSICAL FITNESS AND HEALTH IN THE FORMATION OF HUMAN CAPITAL
}

\author{
EDUCACIÓN FÍSICA EN LAS DIRECTRICES DE LA UNESCO: EL PARADIGMA \\ DE LA APTITUD FÍSICA Y DE LA SALUD EN LA FORMACIÓN DEL CAPITAL \\ HUMANO
}

Giovanni Frizzo*, Maristela da Silva Souza**

\begin{abstract}
Palavras chave: Educação Física. Aptidão física. Organização das Nações Unidas para a Educação, a Ciência e a Cultura.

Resumo: O presente ensaio objetiva analisar o paradigma da aptidão física e da promoção da saúde como perspectiva da Educação Física (EF), a partir das diretrizes da Organização das Nações Unidas para a Educação, a Ciência e a Cultura (UNESCO), que regulam a EF em âmbito internacional. Tomamos como ponto de referência o documento "Diretrizes em Educação Física de Qualidade: para gestores de políticas". Dois aspectos são destacados nessas Diretrizes: o caráter da EF na formação dos indivíduos e a relação causa-efeito da atividade física e saúde. Tais elementos nos permitem indicar que a perspectiva da EF e a do esporte como promotores de saúde e disciplinamento são fatores significativos para a formação do capital humano. Portanto, mais importante do que realizar atividades físicas é aprofundar os conhecimentos das práticas corporais, para que se eleve o patamar de compreensão acerca dos fenômenos, com caráter emancipador.
\end{abstract}

Keywords: Physical Education. Physical fitness. United Nations Educational, Scientific and Cultural Organization.

Palabras clave: Educación Física. Aptitud Física. Organización de las Naciones Unidas para la Educación, la Ciencia y la Cultura

Abstract: This essay analyzes the paradigm of physical fitness and health promotion as a perspective in Physical Education (PE), based on the guidelines of the United Nations Educational, Scientific and Cultural Organization (UNESCO), which regulate PE at international level. Our reference was the document "Quality Physical Education (QPE): guidelines for policy makers". Two aspects are highlighted in these Guidelines: the nature of $\mathrm{PE}$ in the formation of the individuals and the cause-effect relationship between physical activity and health. Such elements allow us to point out that PE and sports as promoters of health and discipline are significant for the formation of human capital. Therefore, more important than performing physical activities is to elaborate on knowledge of bodily practices so that it increases the level of understanding about the phenomena, with an emancipatory character.

Resumen: El presente ensayo tiene por objetivo analizar el paradigma de la aptitud física y de la promoción de la salud como perspectiva de la Educación Física (EF) a partir de las directrices de la Organización de las Naciones Unidas para la Educación, la Ciencia y la Cultura (UNESCO), que regulan la EF en el ámbito internacional. Tomamos como punto de referencia el documento "Directrices en Educación Física de Calidad: guía para los responsables políticos". Dos aspectos se destacan en esas Directrices: el carácter de la EF como medio de formación del individuo y la relación causa efecto de la actividad física y salud. Tales elementos nos permiten indicar que la perspectiva de la EF y del deporte como fomentadores de salud y disciplina son factores significativos para la formación del capital humano. Por lo tanto, más importante que realizar actividades físicas es profundizar los conocimientos de las practicas corporales, para que se eleve el nivel de comprensión sobre los fenómenos con carácter emancipador. .
*Universidade Federal de Pelotas. Pelotas, RS, Brasil.

E-mail: gfrizzo2@ig.com.br

**Universidade Federal de Santa Maria. Santa Maria, RS, Brasil.

E-mail: maristeladasilvasou-za@yahoo. com.br

Recebido em: 29-08-2017 Aprovado em: 26-02-2019 Publicado em: 29-04-2019

DOI: https://doi.org/10.22456/1982-8918.76037 (c) (i) (5) Licence 


\section{INTRODUÇÃO}

O presente ensaio tem por objetivo analisar o paradigma da aptidão física e da promoção da saúde como perspectiva da Educação Física (EF), a partir das diretrizes da Organização das Nações Unidas para a Educação, a Ciência e a Cultura (UNESCO), que regulam a EF em âmbito internacional. Tomamos como ponto de referência para esta análise o documento da UNESCO "Diretrizes em Educação Física de Qualidade: para gestores de políticas", cujo objetivo é o de que este "deve ser utilizado como um guia para uma revisão completa da política e da oferta da Educação Física de Qualidade (EFQ) em seu país" (UNESCO, 2015, p.7). Ou seja, busca regular a EF no plano internacional como orientação para constituir a lógica hegemônica da área, cuja intencionalidade, como demonstraremos, é a formação para o mundo do trabalho subsumido ao capital, pois como bem declara o referido documento:

As Diretrizes fornecem um marco de ação para apoiar gestores de políticas (por exemplo, diretores de departamentos de Estado ou dirigentes e assessores de ministérios) na reforma de políticas no campo de educação física, para acelerar 0 desenvolvimento de diversas dimensões do capital humano de uma forma original e abrangente (UNESCO, 2015, p.5).

A partir da análise documental como procedimento metodológico e de categorias científicas e filosóficas da Economia Política, como capital, trabalho e mercadoria, realizamos uma investigação da relação entre as políticas públicas e a reestruturação produtiva oriunda do agravamento da crise econômica e social que vivenciamos neste período histórico. Com base nas diretrizes da UNESCO, compreendidas aqui como marco regulatório internacional para a $E F$, partimos do pressuposto de que as mudanças socioeconômicas originadas nas necessidades produtivas se desdobram em políticas públicas que estabelecem paradigmas na formação e atuação profissional, cujos desdobramentos concretos são definidores de perspectivas hegemônicas na área da EF, especialmente para a organização do trabalho pedagógico escolar dessa área de conhecimento.

\section{CAPITAL E TRABALHO: APONTAMENTOS INTRODUTÓRIOS}

As demandas e necessidades da esfera produtiva se interpõem para a EF de maneira a formar um determinado tipo de ser humano que reproduza a ideologia dominante e a forma prática alienada (estranhada) da esfera do trabalho capitalista. Essa questão já nos foi contada pela história da EF, a partir da produção clássica da área sob a influência das Ciências Sociais e Humanas, tais como: Medina (1983), Ghiraldelli Jr. (1988), Oliveira (1988), Castellani Filho (1988). Pressupomos existir uma relação em movimento, em que não há determinações impostas arbitrariamente, mas, sim, relações dialéticas - contraditórias e recíprocas - colocadas em movimento por seus agentes históricos e sua configuração de classe social, permitindonos, portanto, sustentar a tese de que se estabelece uma relação entre EF e o sistema social, em que ela não perdeu a sua atualidade e necessidade de análise em vista das dinâmicas próprias de reorganização. Até porque o desenvolvimento histórico do capitalismo não nos permite afirmar que há uma estagnação na sua forma aparente de reprodução da existência humana, em que a EF se configura como parte de um movimento da redefinição do Estado e das formas de subsunção do trabalho ao capital na atualidade. 
Nesse processo, a análise entre capital e trabalho torna-se imprescindível quando objetivamos compreender o fenômeno para além do seu aparente, e, no que se refere à área da EF, compreender como esta se efetiva no âmbito desse movimento.

Fundamentados em Engels (2005), no clássico texto que trata do papel do trabalho na transformação do macaco em homem, podemos dizer que 0 trabalho é a atividade pela qual o ser humano cria a si mesmo em mediação com a natureza; é a condição para a sua realização enquanto ser humano. Os seres humanos são, portanto, as formas com as quais produzem sua existência, enquanto ser genérico, por meio do trabalho. Em um determinado período da história da humanidade, o ser humano confrontou-se com situações em que sua sobrevivência só seria possível com o desenvolvimento de capacidades que ainda não haviam se desenvolvido. A partir da necessidade de sobrevivência é que os antepassados do ser humano (hominídeos) modificaram sua relação com a natureza, estabelecendo não mais uma adaptação pura e simples às condições que se apresentavam pelo meio ambiente, mas uma relação que dependeria da transformação deste para atender às suas necessidades, primeiramente imediatas de sobrevivência e, posteriormente, com o desenvolvimento das civilizações, as necessidades criadas pelas novas formas de produção e reprodução da vida. Essa transformação é a atividade produtiva essencial da existência da humanidade, ou seja, o trabalho. Como afirmou Marx (2008, p. 65-66): "o trabalho, como criador de valores de uso, como trabalho útil, é indispensável à existência do homem - quaisquer que sejam as formas de sociedade -, é necessidade natural e eterna de efetivar o intercâmbio material entre o homem e a natureza e, portanto, de manter a vida humana".

Além do intercâmbio com a natureza, o trabalho também é responsável por estabelecer as relações entre os próprios seres humanos. Surgiram, desse processo, as relações sociais e constituição das primeiras civilizações ou sociedades que, por sua vez, vieram a originar as relações de produção que constituem o mundo do trabalho (ANTUNES, 1999). Porém, se o trabalho significa a objetivação da vida genérica do ser humano, ou seja, o caráter ontológico de sua existência, com o surgimento do modo de produção eminentemente capitalista, o trabalho assume um outro sentido: alienado, explorado e assalariado. 0 trabalho nas sociedades pré-capitalistas não era separado da vida familiar, da religião e do lazer; tinha um caráter de subsistência, em que a troca era apenas residual, somente o pouco excedente da produção era trocado por outras mercadorias. Com o surgimento da indústria e a exploração da classe trabalhadora pelos proprietários dos meios de produção, a atividade econômica tornou-se uma busca incansável pelo lucro, em que a troca se tornou o centro da produção, voltando-se unicamente para a valorização do capital.

Essa conversão da força de trabalho em capital, na forma do assalariamento, é elevada a um grau de universalidade incontestável, é mais do que a simples aceitação de uma imposição externa, configura a subsunção do trabalho ao capital (MARX, 2008), o que não significa apenas uma relação de subordinação do trabalho, mas também uma relação de dependência do ser humano ao capital devido às suas necessidades de subsistência.

Marx (2008), ao elaborar a crítica da economia política, aponta a mercadoria como força motriz do modo de produção capitalista, e a partir dessa análise é que se determina o caráter do trabalho no capitalismo, no qual tudo, inclusive o trabalho, é transformado em mercadoria. As elaborações de Marx (2008) também apontam os elementos componentes do processo de trabalho, tais como: 1) o objeto de trabalho - matéria a que se aplica trabalho; 2) 
meios de trabalho - ferramentas, maquinaria, condições gerais de produção etc; 3) o próprio trabalho - força de trabalho agregada ao objeto capaz de gerar mais-valia. Portanto, a força de trabalho, junto aos meios de produção, constitui as forças produtivas e, como tal, é comprada pelo proprietário dos outros elementos - objeto e meios de trabalho. A quem não detém os meios de produção - quem vive do seu trabalho -, resta vender aquilo que lhe pertence, vender a sua mercadoria: a força de trabalho. Esta, por sua vez, tem que ser vendida no mercado (assim chamado de mercado de trabalho).

O trabalho enquanto força de trabalho, portanto, mercadoria, tem um valor que é determinado, como qualquer outra mercadoria, pelo tempo de trabalho necessário à sua produção e, por consequência, à sua reprodução.

Dada a existência do indivíduo, a produção da força de trabalho consiste em sua manutenção ou reprodução. Para manter-se, precisa o indivíduo de certa soma de meios de subsistência. 0 tempo de trabalho necessário à produção da força de trabalho reduz-se, portanto, ao tempo de trabalho necessário à produção desses meios de subsistência necessários a manutenção de seu possuidor (MARX, 2008, p. 201).

A soma desses meios de subsistência é que vai estabelecer a quantidade de trabalho necessário para a produção e reprodução da força de trabalho, suficiente para manter o ser humano em condições de vender, diariamente, a sua mercadoria. Ou seja, "o valor da força de trabalho reduz-se ao valor de uma soma determinada de meios de subsistência. Varia, portanto, com o valor dos meios de subsistência, ou seja, com a magnitude do tempo de trabalho exigido para sua produção" (MARX, 2008, p. 202). Além dos meios de subsistência, acresce-se ao tempo necessário à produção da força de trabalho o tempo de qualificação para determinadas atividades (por exemplo: da medicina, da engenharia, da agronomia, da pedagogia etc.). Assim, o valor de troca dessa força de trabalho se identifica diretamente com a sua qualificação profissional e a necessidade desta para cada período histórico.

Desde a década de 1960, quando Theodore Schultz e a Escola de Chicago desenvolveram a teoria do capital humano, a educação e os processos de formação têm sido direcionados para a qualificação profissional, ou seja, que se subentendem como preparação para o mercado de trabalho. A teoria do capital humano surgiu da preocupação em explicar os ganhos de produtividade gerados pelo "fator humano" na produção. De acordo com Minto (2010), a conclusão de tais esforços redundou na concepção de que o trabalho humano, quando qualificado por meio da educação, era um dos mais importantes meios para a ampliação da produtividade econômica e, portanto, das taxas de lucro do capital. Aplicada ao campo educacional, a ideia de capital humano gerou toda uma concepção tecnicista sobre o ensino e sobre a organização da educação, o que acabou por mistificar seus reais objetivos. Sob a predominância dessa visão tecnicista, passou-se a disseminar a ideia de que a educação é o pressuposto do desenvolvimento econômico, bem como do desenvolvimento do indivíduo, que, ao educar-se, estaria "valorizando" a si próprio, na mesma lógica em que se valoriza o capital.

Essa teoria, portanto, deslocou para o âmbito individual os problemas da inserção social, do emprego e do desempenho profissional e fez da educação um fator econômico, numa equação perversa que equipara capital e trabalho como se fossem ambos igualmente meros "fatores de produção" (no sentido das teorias econômicas clássicas). Como afirma Frigotto, 
dependente, e se afirma a ideia de que a ascensão e mobilidade social têm um caminho garantido via escolaridade, mediante empregos bem remunerados (FRIGOTTO, 2009, p. 131-132).

Nessa mesma relação do sistema educacional voltado para o desenvolvimento econômico é que as diretrizes da UNESCO apontam "para acelerar o desenvolvimento de diversas dimensões do capital humano de uma forma original e abrangente (UNESCO, 2015, p.5).

Portanto, essas diretrizes indicadas estabelecem patamares para a definição de políticas públicas, em cada país membro da UNESCO, que devem ser operacionalizadas pelos governos para desenvolvimento do capital humano. Aqui, entrelaçam-se as esferas econômica e política, entre Estado e capital, na medida em que as demandas produtivas tornam-se a base para a implementação de políticas públicas pelos governos subordinados à perspectiva hegemônica do modo de produção.

\section{APTIDÃO FÍSICA E SAÚDE NA FORMAÇÃO DO CAPITAL HUMANO}

A lógica do capital humano opera com a produção da mercadoria força de trabalho, tanto do ponto de vista objetivo quanto subjetivo, tendo as políticas públicas e as instituições de ensino como o espaço privilegiado para essa produção. Na análise de Frizzo (2012), no caso da EF e do esporte, as duas principais categorias estruturantes na atualidade são 0 disciplinamento para a esfera da produção e reprodução da vida no sistema do capital; e a empregabilidade como a aquisição de competências necessárias para almejar melhores lugares no mercado de trabalho (o que não significa conseguir emprego, apenas disputar com mais competitividade), ou seja, uma capacidade flexível de adaptação individual às demandas do mercado.

Neste cenário, apresenta-se bastante elucidativa a propaganda da Associação Cristã de Moços (ACM), ainda no início dos anos 1980, ao apontar em seus materiais que: "[...] funcionários bem preparados fisicamente produzem mais e melhor" (CASTELLANI FILHO, 1988, p. 112). Ou mesmo, atualmente, o material publicitário do SENAI, que diz: "A indústria pede, nós formamos" (BOPSIN, 2016, p. 30).

Na relação que se estabelece entre EF e capital, a busca pela legitimidade da EF sob o prisma do paradigma da atividade física e da promoção da saúde apresentou-se bastante efervescente no início dos anos 1990, sofrendo análises e críticas quanto à sua visão biologicista e funcionalista que, na análise de Ferreira (1995), ao objetivar promover a adoção por parte do educando de um modo de vida saudável, acaba restringindo-se:

\footnotetext{
A ideia de que todo (organismo social) é positivo e funcional, não devendo ser contestado (de fato não o é): há, entretanto, uma disfunção no organismo, cabendo à EF intervir (neste órgão doente) revertendo esse quadro disfuncional para que 0 organismo volte a funcionar harmonicamente. Logo, a visão funcionalista é clara, e reflete uma ideologia liberal implícita (FERREIRA, 1995, p.22).
}

Acreditamos que, mais uma vez, através das diretrizes da UNESCO, a EF comprometese com um projeto direcionado pela visão biologicista da área, que sob o enfoque das Ciências Naturais não dialoga com as Ciências Sociais, não contemplando uma educação para a saúde que inclua "a organização e mobilização em defesa da saúde pública, sucateada e privatizada no neoliberalismo" (FERREIRA, 1995, p.30). 
O discurso que expressa a imbricação política do campo da EF com a área da saúde (tal como definida pela Capes e pelas políticas educacionais de formação de professores e conteúdos escolares) trata fundamentalmente de utilizar-se de um campo do conhecimento das manifestações da cultura corporal para uma função utilitária de promover a saúde dos trabalhadores, sob a perspectiva biomédica, por meio da realização de atividades físicas ao longo da vida e, com isso, responsabilizar os indivíduos por sua vitalidade para o mercado e produção de lucro para o proprietário de sua força de trabalho. Nessa esteira, Bagrichevsky e Estevão (2005) argumentam que se, por um lado, é parcialmente aceitável a generalização da existência de benefícios orgânicos decorrentes de algumas modalidades de exercícios físicos, por outro lado, essa argumentação é "[...] discutível, na medida em que pretende sustentar uma política conservadora, uma dimensão moral que responsabiliza cada pessoa por seu próprio adoecimento e desconsidera a dinâmica sistêmica e multifária que influencia os estados de enfermidade humana" (BAGRICHEVSKY; ESTEVÃO, 2005, p. 67).

Matiello Jr. etal. (2008) denunciam que o paradigma de risco instalado hegemonicamente no campo da saúde é que tem marcado a produção do conhecimento da EF, trazendo para a área um limite na sua atuação política e científica, uma vez que estabelece prioridades descontextualizadas sobre a saúde de nossa população e, consequentemente, na sua relação com a prática da atividade física. Na relação entre causa (exposição a fatores de risco) e efeito (doenças), a EF também realiza uma associação de causalidade quando apresenta uma relação aparente entre doenças (efeito) e falta de atividade física (causa).

Esta lógica favorece a perpetuação de sistema que tem como inerente a
possibilidade de causar danos aos trabalhadores, pois, agindo-se no nível de
superficialidade, não se altera a essência dos processos em que se originam
esses problemas. Fica implícita a ideia de que viver é um risco e que, portanto,
é normal conviver com a possibilidade de agressões do trabalho e, grosso modo,
deveremos nos contentar com as promessas de redução dos riscos ao mínimo
possível (MATIELLO JR. et al., 2018, p.46).

Os autores propõem que, em vez do termo exposição (a fatores de risco), usado para se referir à situação em que se está passível de riscos às doenças, é preferível o termo imposição (a fatores de risco), pois, na atual sociedade de classes, não se tem liberdade para fazer escolhas, ocorrendo submissão a processos que, sem dúvida, geram destruição da saúde.

Portanto, a relação causa-efeito entre exercício físico e saúde é determinante para essa concepção de que indivíduos praticantes de atividades físicas são mais saudáveis, sendo instruídos a adotar um "estilo de vida ativo". Essa ideia, segundo Bagrichevsky e Estevão (2005, p. 69), "de que seria possível obter saúde, através do acesso às atividades corporais oferecidas nesse nicho mercadológico, ratifica a noção simbólica de 'saúde conquistada', quer seja pelo envolvimento em suas práticas, quer seja pela utilização dos produtos a elas agregadas".

A saúde passa, então, a ser concebida não como um direito social e dever do Estado, mas responsabiliza o indivíduo por suas escolhas, seu modo de vida e suas moléstias. Ainda, concebe os exercícios físicos como receita e remédio, julgando-se que por meio deles e sem mudar as condições materiais de vida seja possível adquirir o corpo saudável, ágil e disciplinado exigido pela nova sociedade capitalista (SOARES et al., 1992).

Em relação ao esporte, as características da competição exacerbada, do disciplinamento à regras impostas, a sobrepujança sobre adversários, dentre outros aspectos, podem ser 
considerados "uma forma de controle social, pela adaptação do praticante aos valores e normas dominantes defendidos para a 'funcionalidade' e desenvolvimento da sociedade" (SOARES et al., 1992, p. 71). Sobre o ensino do esporte na escola, Kunz (2004, p. 125) aponta que "enquanto cópia irrefletida do esporte competição ou de rendimento, só pode fomentar vivências de sucesso para uma minoria e o fracasso ou vivência de insucesso para a grande maioria". Tal qual a competição predatória do mercado de trabalho, essa forma de trabalhar com o conteúdo esporte na EF Escolar contribui sobremaneira para a adaptação e "naturalização" de relações individualistas e competitivas.

Tais elementos nos permitem indicar que a perspectiva da EF e do esporte como promotores de saúde e disciplinamento para a vida social é um fator significativo para a produção e reprodução da força de trabalho enquanto mercadoria a ser produzida e reproduzida pelos sujeitos sociais. Nesse sentido, a regulação da EF em âmbito internacional, a partir das estratégias definidas por organismos internacionais, tem buscado estabelecer em abrangência global quais formas de comportamento podem ser consideradas "saudáveis" e "de risco" às pessoas (CASTIEL, 2002). Entretanto, como afirma Castiel (2002, p. 70), mais do que recomendações, "tais normas engendram, com sutileza, aspectos descontextualizados, preconceituosos e elitistas, já que nem sempre suas preconizações são factíveis a todas as nações e aos diferentes estratos sociais daquelas que as adotam".

O documento declara que o objetivo da EFQ é: "[...] um jovem instruído fisicamente, com habilidades, confiança e compreensão para continuar participando de atividades físicas ao longo de toda a vida. Assim, a EF deve ser reconhecida como a base de uma participação cívica inclusiva e contínua ao longo da vida" (UNESCO, 2015, p. 20).

$\mathrm{A} E F$, tendo como papel central a instrução física para participação cívica, remonta à ideia de "adestramento social", em que a potencialidade física deve ser instruída para corpos preparados para suportar a incerteza e a insegurança do mercado, bem como a de "reconhecer e administrar riscos, cumprir as tarefas designadas e aceitar a responsabilidade para com seu próprio comportamento. Os alunos aprendem formas de lidar com o sucesso e com 0 fracasso e, além disso, como avaliar o desempenho diante de suas realizações anteriores e as de outros" (UNESCO, 2015, p. 14). Tais elementos dizem respeito a dotar os indivíduos de comportamentos flexíveis e comparativos que lhes permitam "ajustar-se às condições de uma sociedade em que as próprias necessidades de sobrevivência não estão garantidas" (SAVIANI, 2007, p. 435).

De acordo com o documento, o atrelamento da EF aos aspectos econômicos não se restringe somente à produção e reprodução da força de trabalho, mas também se desdobra em políticas que se propõem a reduzir investimento em saúde - "investimento público na EF é largamente compensado pelos altos dividendos na economia em saúde" (UNESCO, 2015, p. 4) - e estimular relações entre o setor privado e o público, "por meio de parcerias com organizações não governamentais" (UNESCO, 2015, p. 17), ou mesmo com o desenvolvimento de parcerias entre escolas, organizações esportivas comunitárias e clubes privados. Ainda na questão do investimento da $E F$, as diretrizes preveem que os países devam revisar seus modelos de financiamento da formação de professores de EF e da própria EF, "levando em consideração o retorno dos investimentos, baseado em evidências, que pode gerar ganhos, tanto sociais como econômicos" (UNESCO, 2015, p. 22). Essas diretrizes apontam, portanto, para a relação direta entre o setor público e o privado, reconfigurando o papel do Estado na 
garantia dos direitos sociais, assim como no retorno econômico para a esfera mercadológica, determinadas pelos investimentos em EF.

Outro aspecto bastante recorrente nas diretrizes é o caráter utilitário da EF para as políticas públicas, na medida em que se pressupõe que o atendimento às diretrizes da UNESCO pode repercutir em diferentes aspectos da vida social em todas as partes do mundo, como uma salvaguarda universal para os diversos problemas da sociedade, tais como: a EF pode "salvar vidas ao proteger crianças e jovens contra a exploração e o perigo, incluindo casos de casamento precoce forçado, e recrutamento em forças armadas, em grupos armados ou no crime organizado" (UNESCO, 2015, p. 28); também com finalidade de fazer uso da EF para 0 aprendizado de outras questões, pois "pode realizar contribuições únicas para a aprendizagem em outras disciplinas e desenvolver habilidades transferíveis para fundamentar atividades fora do currículo escolar" (UNESCO, 2015, p. 42); demarcando, ainda, que "a nossa visão é clara: o esporte e a EF são essenciais para a juventude, para vidas saudáveis, para sociedades resilientes e para combater a violência" (UNESCO, 2015, p. 4).

As Diretrizes da UNESCO também apontam algumas questões que estão em contradição com as atuais políticas públicas educacionais no Brasil, especialmente em dois sentidos:

1) A recente aprovação da Reforma do Ensino Médio (MPV 746/2016) retirou a obrigatoriedade da disciplina de EF no currículo escolar, estabelecendo apenas que a sua "prática" seja garantida no currículo do ensino médio. Nas Diretrizes da UNESCO, orienta-se que "é essencial que os governantes tomem medidas políticas para garantir que a disciplina assegure seu lugar de direito nos currículos escolares, e que, consequentemente, os estudantes se beneficiem com a exposição aos campos alternativos de aprendizagem" (UNESCO, 2015, p. 6). Assim como "para assegurar o lugar da EF no currículo escolar, a oferta não deve ser marginalizada em favor de outras disciplinas e/ou eventos que requerem recursos" (UNESCO, 2015, p. 54).

2) O Programa Escola Sem Partido (PESP), que tem sido tratado nas esferas legislativas e judiciárias da União, estados e municípios, trata de restringir o acesso ao conhecimento na escola através de restrições de temáticas como gênero, sexualidade e religião, dentre outras, que não deverão ser abordadas pelas escolas, caso o PESP seja aprovado nas esferas administrativas correspondentes. Nas Diretrizes da UNESCO, explicita-se que é preciso que "políticas efetivas devem ser elaboradas com o objetivo de prevenir e, principalmente, impedir o abuso, a violência física ou psicológica, o bullying homofóbico e a violência baseada em gênero" (UNESCO, 2015, p. 21).

Portanto, dentre as orientações das Diretrizes da UNESCO para a EF, temos, por um lado, a consolidação de uma política de EF definida a partir das necessidades de produção e reprodução da força de trabalho, tanto do ponto de vista objetivo quanto subjetivo. $\mathrm{E}$, por outro lado, também temos algumas orientações que buscam efetivamente favorecer a consolidação da EF enquanto uma disciplina presente no currículo escolar e que trate também de temáticas que avancem na qualidade da educação e da formação escolar, ao tratar das questões referentes a opressões de gênero, sexualidade, étnico-raciais, religiosas etc.

A análise desse contexto carregado de contradições nos remete a entender a relação de subordinação da área da EF à lógica do mercado. O mercado orienta para uma formação 
pautada em princípios da inclusão, materializada, porém, em uma sociedade excludente. Com isso, a EF faz parte de um jogo em que os interesses econômicos e a formação do capital humano pautam a sua trajetória, tornando a sua rotina e o seu futuro reféns das exigências necessárias para a formação deste atual ou futuro trabalhador. Tal situação se agrava quando a forma hegemônica da EF se fundamenta, enquanto área de conhecimento, nos princípios de "um sistema montado sobre a desigualdade e a exploração dos trabalhadores" (FRIGOTTO, 2013, s.p), não se pautando nos seus quadros contra-hegemônicos da área que podem, um dia, levar a uma emancipação humana, pois "a apropriação ativa e consciente do conhecimento é uma das formas de emancipação humana" (SOARES et al., 1992, p.17).

\section{CONSIDERAÇÕES FINAIS}

Ao analisarmos o paradigma da aptidão física e da promoção da saúde como perspectiva da EF a partir das diretrizes da UNESCO que a regulam em âmbito internacional, identificamos que tais diretrizes buscam estabelecer marcos políticos para que as nações vinculadas a essa organização desenvolvam um mesmo projeto de sociedade baseado na regulação de mercado e na produção de mercadorias, incluindo a força de trabalho.

Nesse sentido, concordamos com Lima (2005, p. 80), quando diz que:

As políticas promovidas por estes sujeitos políticos coletivos do capital - Fundo Monetário internacional/FMl; Grupo Banco Mundial/BM,1 Banco Interamericano de Desenvolvimento/BID; Organização das Nações Unidas para a Educação, a Ciência, e a Cultura/UNESCO e mais recentemente, a Organização Mundial do Comércio/OMC - vêm orientando um conjunto de reformas econômicas e políticas realizadas nos países de periferia do capitalismo. Estas políticas configuram 0 projeto neoliberal de sociabilidade vigente no contexto mundial pós anos 70 do século passado. Um capitalismo relançado que vem desenvolvendo as bases materiais e ideológicas para a intensificação da mundialização financeira.

Na especificidade da EF, operam de forma objetiva e subjetiva a produção e reprodução da força de trabalho, seja através do disciplinamento para a vida social e produtiva, seja para a garantia de condições físicas e corporais de suportar a complexidade do mercado de trabalho, a precarização do trabalho ou mesmo as jornadas laborais, cada vez mais extensas e intensas.

A complexidade das mudanças sociais das últimas décadas tem modificado sobremaneira as relações de produção, tanto sobre a propriedade quanto a troca (distribuição) e as relações de trabalho. Se observamos que o desenvolvimento de forças produtivas tem buscado diminuir o trabalho vivo na produção, ao mesmo tempo em que se aumenta a oferta de força de trabalho total, por um cálculo simples identificamos uma grande parcela da sociedade que não consegue acessar o emprego, ou seja, o aumento do desemprego é uma tendência do desenvolvimento do sistema do capital na atualidade; assim como a crise do sistema social vigente tem feito com que a classe dominante busque suas "soluções" por meio da utilização do fundo público, isto é, criando mecanismos e políticas para tornar os direitos sociais em formas de lucratividade, através das privatizações ou restrição de investimento em serviços públicos. Tais elementos se desdobram em uma nova forma de sociabilidade para a população, para quem os direitos sociais não são garantidos pelo Estado e, portanto, cabe a cada indivíduo

10 Grupo Banco Mundial compreende: o Banco Internacional de Reconstrução e Desenvolvimento (BIRD), a Corporação Financeira Internacional (IFC), a Agência Multilateral de Garantia de Investimentos (MIGA), a Associação Internacional de Desenvolvimento (IDA), o ICSID (Centro Internacional para Resolução de Disputas e Investimentos) e, mais recentemente, passou para a coordenação do Banco o GEF (Fundo Global para o Meio Ambiente). 
"conquistar" tais direitos de forma individualizada, uma competição própria da sociedade em que o mercado é regulador da vida.

Nesse sentido, dois aspectos são destacados das Diretrizes da UNESCO em estudo: um primeiro sobre o caráter da EF na formação dos indivíduos e seu papel na produção da força de trabalho, em que seu caráter instrumental estabelece como objetivo o disciplinamento para o mercado em que a lógica competitiva do esporte, a submissão hierárquica de poder, 0 cumprimento de regras, a adaptação ao sucesso e o fracasso, entre outros aspectos, dotam a EF de papel importante na formação escolar, no sentido de preparar cada sujeito para colocar sua mercadoria à venda no mercado; o segundo aspecto diz respeito à relação causa-efeito da atividade física e saúde, cuja função principal é a reprodução da força de trabalho, ou seja, cada trabalhador deve "conquistar" a sua saúde por meio de um "estilo de vida ativo" e da prática regular de exercícios físicos tomados como medicamentos para finalidades externas às próprias práticas corporais, com o intuito de estar "apto e saudável" para suportar as condições de insegurança e instabilidade na vida social regulada pelo mercado.

Apesar de todo o discurso de inclusão que o documento apresenta, conserva-se a concepção de formação de capital humano, incluindo na exclusão, ou, como nos declara Kuenzer (2002), é um processo dialético entre "Exclusão includente e inclusão excludente". Até porque, como diz Frigotto (2006, n.p.), "a direção que assume a relação trabalho e educação nos processos formativos não é inocente. Traz a marca dos embates que se efetivam no âmbito do conjunto das relações sociais".

Acreditamos que a EF deva contrariar o seu histórico de subordinação aos sistemas políticos e econômicos e dialogar com as necessidades históricas dos trabalhadores, de maneira a expressar o seu conhecimento de forma científica, histórica e cultural. Para tanto, a perspectiva contra-hegemônica da EF, que tem por base a cultura corporal produzida historicamente pela humanidade, requer uma formação escolar referenciada na apropriação do conhecimento das suas manifestações, tanto do ponto de vista biológico quanto econômico e social. Portanto, mais importante do que realizar atividades físicas é aprofundar o conhecimentos das práticas corporais, para que se eleve o patamar de compreensão acerca dos fenômenos, com caráter emancipador. Difere, portanto, de uma perspectiva em que se objetiva realizar atividades físicas, acreditando que sua consequência será imediatamente a adoção de estilos de vida para a "conquista" da saúde.

\section{REFERÊNCIAS}

ANTUNES, Ricardo. Os Sentidos do Trabalho: ensaio sobre a afirmação e a negação do trabalho. São Paulo: Boitempo, 1999.

BAGRICHEVSKY, Marcos; ESTEVÃO, Adriana. Os sentidos da saúde e a Educação Física: apontamentos preliminares. Arquivos em Movimento, v.1, n.1, p.65-74, jan.jjun. 2005.

BOPSIN, Andressa. Saúde docente e a precarização do trabalho no curso de educação física na rede privada de ensino superior. 2016. 131f. Dissertação (Mestrado em Educação Física) - Escola de Educação Física, Universidade Federal de Pelotas, Pelotas, 2016. 
BRASIL. Medida provisória n. 746, de 22 de setembro de 2016. Institui a Política de Fomento à Implementação de Escolas de Ensino Médio em Tempo Integral, altera a lei n. 9.394, de 20 de dezembro de 1996, que estabelece as Diretrizes e Bases da Educação Nacional, e a lei n. 11.494 de 20 de junho 2007, que regulamenta o Fundo de Manutenção e Desenvolvimento da Educação Básica e de Valorização dos Profissionais da Educação, e dá outras providências. Brasília, DF, 23 set. 2016. Disponível em: http://www.planalto.gov.br/ccivil 03/ ato2015-2018/2016/ Mpv/mpv746.htm. Acesso em: 4 nov. 2017.

CASTELLANI FILHO, Lino. Educação Física no Brasil: a história que não se conta. São Paulo: Papirus, 1988.

CASTIEL, Luis David. A medida do possível: risco e saúde. In: CICLO DE CONFERÊNCIAS 'A SAÚDE EM DEBATE NA EDUCAÇÃO FÍSICA'. 1. Coleção de Vídeos 'A Saúde em Debate na Educação Física'. Rio de Janeiro: GTT1/ CBCE, 2002. FITA 2 (120 min), VHS.

ENGELS, Friederich. Sobre o Papel do Trabalho na Transformação do Macaco em Homem. In: ANTUNES, Ricardo. A Dialética do Trabalho. 2. ed. São Paulo: Expressão Popular, 2005.

FERREIRA, Marcelo Guina. Teoria da Educação Física: Bases e propostas pedagógicas. In: FERREIRA NETO, Amarílio; GOELLNER, Silvana Vilodre.; BRACHT, Valter (orgs.). As Ciências do Esporte no Brasil. Campinas: Autores Associados, 1995. p. 193-224.

FRIGOTTO, Gaudêncio. Escola e trabalho numa perspectiva histórica: contradições e controvérsias. Sísifo - Revista de Ciências da Educação. Lisboa: n. 9, p. 129-136, maio/ago. 2009.

FRIGOTTO, Gaudêncio; CIAVATTA, Maria; RAMOS, Marise. O Trabalho como princípio educativo no projeto de educação integral de trabalhadores - Excertos. 2006. Disponível em: http://redeescoladegoverno.fdrh.rs.gov.br/upload/1392215839 0\%20TRABALHO\%20COMO\%20 PRINC\%C3\%8DPIO\%20EDUCATIVO\%20NO\%20PROJETO.pdf. Acesso em: 18 ago. 2017.

FRIGOTTO, Gaudêncio. Novos fetiches mercantis da pseudo-teoria do capital humano no contexto do capitalismo tardio. 2013. Disponível em: http://www.sinproeste.org.br/wp-content/ uploads/2013/04/O-rejuvenecimento-da-teoria-do-capital-humano-no-contexto-do-capitalismo-tardio. pdf. Acesso em: 3 jul. 2017.

FRIZZO, Giovanni. A Organização do Trabalho Pedagógico da Educação Física na Escola Capitalista. 2012. 264f. Tese (Doutorado em Ciências do Movimento Humano) - Escola de Educação Física, Universidade Federal do Rio Grande do Sul, Porto Alegre, 2012.

GHIRALDELLI JÚNIOR, Paulo. Educação Física Progressista: a pedagogia crítico-social dos conteúdos e a Educação Física brasileira. São Paulo: Loyola, 1988.

KUENZER, Acácia Zeneida. Exclusão includente e inclusão excludente. In: LOMBARDI, José Claudinei; SAVIANI, Demerval; SANFELICE, José Luis. (orgs.). Capitalismo, trabalho e educação. Campinas: Autores Associados, 2002. p.77-95.

KUNZ, Elenor. Transformação Didático-pedagógica do Esporte. 6. ed. ljuí: Unijuí, 2004.

LIMA, Kátia Regina de Souza. Reforma da educação superior nos anos de contra-revolução neoliberal: de Fernando Henrique Cardoso a Luis Inácio Lula da Silva. 2005. 466f. Tese (Doutorado em Educação) - Universidade Federal Fluminense, Rio de Janeiro, 2005.

MARX, Karl. 0 Capital: crítica da economia política. Livro 1. 22. ed.. Rio de Janeiro: Civilização Brasileira, 2008. 2 v. 
MATIELLO JÚNIOR, Edgard et al. Superando riscos na atividade física relacionada à saúde. Movimento, v. 14, n. 1, p. 39-61, jan./abr. 2008.

MEDINA, João Paulo. A Educação Física cuida do corpo... e "mente": bases para a renovação e transformação da educação física. Campinas: Papirus, 1983.

MINTO, Lalo Watanabe. Teoria do Capital Humano. In: HISTEBR. Glossário online, 2010. Disponível em: http://www.histebr.fae.unicamp.br. Acesso em: 15 ago. 2010.

OLIVEIRA, Vitor Marinho de. 0 que é Educação Física? 2. ed. São Paulo: Brasiliense, 1988.

SAVIANI, Dermeval. História das Ideias Pedagógicas no Brasil. São Paulo: Autores Associados, 2007.

SOARES, Carmen Lúcia et al. Metodologia do Ensino de Educação Física. São Paulo: Cortez; 1992.

UNESCO. Diretrizes em Educação Física de Qualidade: para gestores de políticas. Brasília: UNESCO, 2015. 